\title{
A Rare Case of Adenoid Cystic Carcinoma of the Breast: Discussion and Review of the Literature
}

\author{
Saad Lannaz, Imane Ouziane, Youssef Bensouda, Hind Mrabti, Hassan Errihani \\ Department of Medical Oncology, National Institute of Oncology, Rabat, Morocco \\ Email: lannazsaad@gmail.com
}

Received 24 May 2014; revised 23 June 2014; accepted 16 July 2014

Copyright (C) 2014 by authors and Scientific Research Publishing Inc.

This work is licensed under the Creative Commons Attribution International License (CC BY).

http://creativecommons.org/licenses/by/4.0/

(c) (i) Open Access

\begin{abstract}
Adenoid cystic carcinoma (ACC) of the breast is a rare type of primary breast cancer with a favorable prognosis, despite its triple-negative status. There has been no consensus regarding treatments. We will report a case of Adenoid cystic carcinoma of the breast presented with localized disease and no axillary lymph node metastases. We performed a radical mastectomy with axillary lymph node dissection, with a favorable clinical course and we will describe the clinic pathologic features of ACC of the breast and review the current literature.
\end{abstract}

\section{Keywords}

Adenoid Cystic Carcinoma, Triple-Negative Breast Carcinoma

\section{Introduction}

Adenoid cystic carcinoma (ACC) of the breast is a rare type of primary breast cancer representing only $0.1 \%$ of all breast carcinomas [1]. It was first described by Geschickter and Copeland in 1945 [2]. In contrast to extramammary ACC, the prognosis of ACC arising in the breast is excellent. ACC of the breast is often localized, with a lower risk of metastases of lymph nodes or uncommon distant metastases [3].

Doctors have not established guidelines to treat this kind of cancer in because of its rarity and the large variation in the patterns of practice.

\section{Observation}

A 47-year-old female is complaining of a lump in the right breast which had appeared 12 months earlier with Mastodynia. In the physical examination, a mass was palpable with an approximate size of $4 \mathrm{~cm}$. The superficial 
lymph nodes were not palpable.

Ultrasonography revealed an ill-defined mass in the right breast. Mammography revealed a large irregular dense shadow behind the right nipple (Figure 1 and Figure 2).

Results of a subsequent diagnostic core biopsy revealed an Adenoid cystic carcinoma. The patient underwent a radical mastectomy and axillary lymph node dissection. The tumor was found to be an ACC measuring $25 \times$ $20 \mathrm{~mm}$ with low nuclear grade. No metastatic axillary lymph nodes were observed. IHC was negative for ER, PR, and HER2 expression. The patient did not receive adjuvant radiotherapy or chemotherapy. The patient has been free of recurrence during 8 months of follow-up.

\section{Discussion}

ACC of the breast is a rare type of primary breast cancer and statistics show that this tumer represent only $0.1 \%$ of all of all breast neoplasms [1]. Case reports and clinical case series are the only sources of information on ACC of the breast. It usually affects women (five cases male described), mean age of 50 - 65 years [1]. ACC is a slow-growing tumor.

A palpable breast mass can be considered as the most common presenting symptom of breast ACC, commonly located in the area of the areola. Spontaneous pain in a patient may be attributable to the perineural inva-

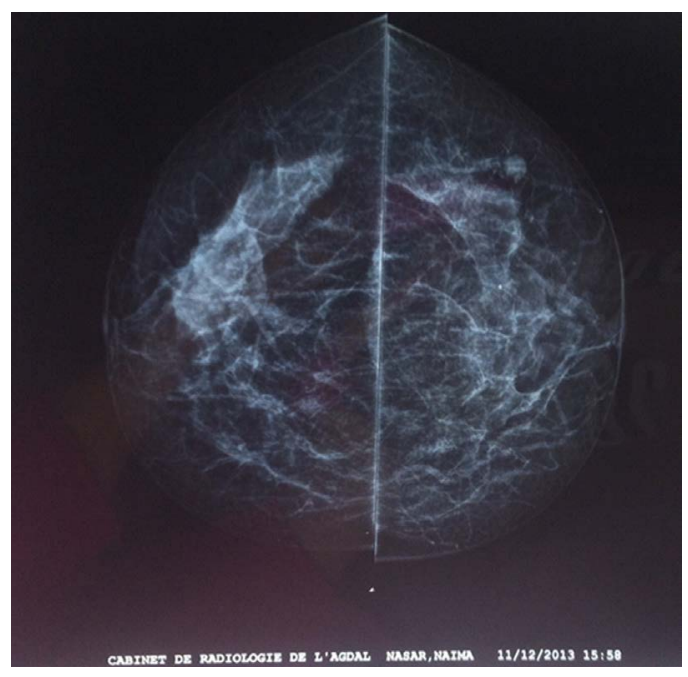

Figure 1. Mammography face profil revealed a large irregular dense shadow behind the right nipple.

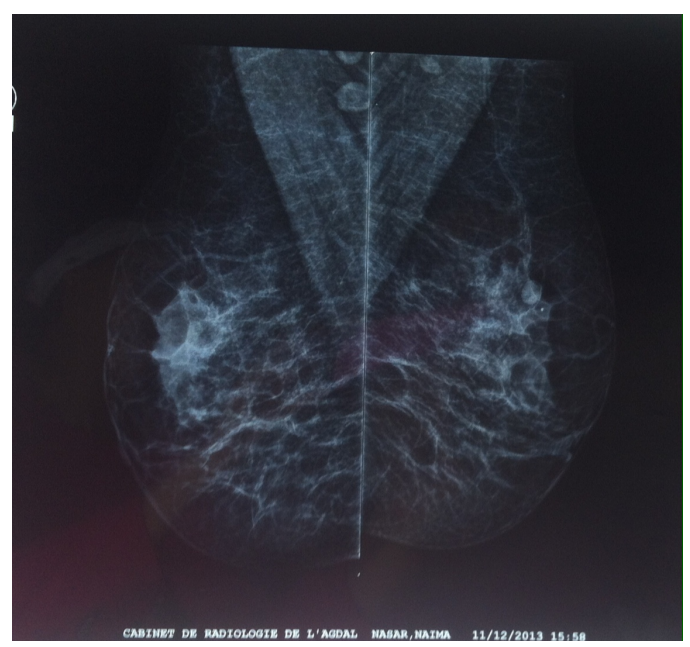

Figure 2. Mammography external profil. 
sion of the tumor. However, this symptom is uncommon. These pains can sometimes detect local recurrences [4].

Mammographic diagnosis is difficult and few studies have described the imaging features of ACC [5]. These aspects are not specific, ranging from well-circumscribed mass with ill-defined, and with more or less architectural distortion but rarely microcalcifications. The differential diagnosis with fibroadenoma, mucinous carcinoma or DIC can be difficult [6], and can sometimes be helped by Ultrasound or MRI [7]. Lymph node metastases as well as distant metastases of ACC in the breast are rare. Sumpio et al. reviewed 120 cases from the literature and showed lymph node metastases in only 4 cases and distant metastases in only 8 cases, the majority of which occurred in the lung [8].

ACC of the breast and ACC originating from salivary glands have the same histopathologic features.

ACC is normally negative for both ER and PR expression not to mention that it does not show HER2/neu gene amplification. It performs the same diagnostic criteria as triple negative breast carcinoma basal phenotype (RE-, RP-, HER-2-neu-, CK5/6+, KIT+) [9]. A recent study showed that these tumors have a mRNA expression profile similar to that of invasive ductal carcinoma Grade III triple negative basal phenotype and a high risk of metastasis by the expression signature of 70 genes Amsterdam [10]. However, their prognosis is much more favorable than ITC triple negative. This could be related to a sub-expression in these tumors for genes related to the migration, proliferation and the immune response. The immunohistochemical profile of ACC makes it difficult to classify. It is distinguished by its dual cell population, first of all, by the basaloid cells that are similar to myoepithelial cells (p63+, AML+, vimentin+) but express high molecular weight keratins (CK5/6, CK14), and second of all, by glandular cells that resemble to luminal cells (CK8/18+, CK5/6+) but did not express hormone receptors. In addition, the CD44/CD24 profiles observed in these two cellular compartments [basaloid cells (CD44+/CD24-) and glandular cells (CD44-/CD24+)] could suggest a double pass from breast pluripotent stem cells with myoepithelial differentiation and luminal incomplete. Nevertheless, we must remain cautious about the interpretation of these immunohistochemical data currently controversies on the recognition of stem cells in breast pathology.

The optimal treatment of ACC of the breast has not yet been determined due to its low incidence. The reviewed literature shows several surgical treatment modalities ranging from a simple lumpectomy without radiotherapy to a radical mastectomy. The radical mastectomy is not advised due to the high risk of physical and psychological damage to patients and the low incidence of nodal metastasis of the tumor. Guidelines for the extent of resection have not yet been established. Leeming et al. [11], who evaluated 24 cases, found that $37.5 \%$ of patients had local recurrence of ACC after undergoing local excision only. McClenathan et al. [12] suggested that even limited lymph node dissection was unwarranted, as a result of the fact that the rate of axillary lymph node metastasis is very low, the role of ALND for patients with ACC is still undefined. Instead, the simple mastectomy has widely been used and is preferred by many surgeons. Although the relationship between margin status and recurrence may not be clear, the simple lumpectomy has the advantages of lower operative damage, less postoperative discomfort and faster recovery; however, it is associated with unacceptably high rates of local recurrence.

Many retrospective studies have shown that adjuvant radiotherapy may be effective for local control and survival in patients with ACC of the breast [13] [14].

The value of systemic adjuvant chemotherapy for ACC of the breast has not been established due to incomplete data. In the 13th Saint Gallen IBCC 2013, they don't recommend a adjuvant chemotherapy for ACC if node negative [15]. In the ESMO guidelines, the ACC is the exception of triple negative tumors that cannot benefit from adjuvant chemotherapy [16].

Distant metastases from ACC of the breast are infrequent, and they happen without lymph node involvement [11]. The lung is the most usual site of metastasis. Bone, liver, and kidney are also sites of metastasis for both patients with ACC of the breast and ACC of the salivary glands [13].

The overall survival rate is favorable: Millar et al. [17] show a rate of $88 \%, 75 \%$ and $60 \%$ in 5,10 and15 years. Arpino et al. [18] show a rate of $100 \%$ at five years and $93.8 \%$ at ten years. The mortality in the literature is $7.1 \%$. These data of long-term survival are explained by long delays onset of local recurrence and metastasis. Natural history of these tumors therefore encourages continuing long-term monitoring.

\section{Conclusion}

ACC of the breast is a type of rare carcinoma with relatively typical especially the character triple negative. But 
it generally has a favorable clinical course. Distant metastasis and late recurrence can occur, and long-term follow-up is required. There is still no standard treatment for this type of tumer. Further valuation of the roles of breast preserving surgery, ALND, and adjuvant treatment is needed. Additional clinical experience is also needed in establishing the optimal guidelines for treatment of ACC of the breast.

\section{References}

[1] Law, Y.M., Quek, S.T., Tan, P.H. and Wong, S.L. (2009) Adenoid Cystic Carcinoma of the Breast. Singapore Medical Journal, 50, e8-e11.

[2] Geschickter, C.F. and Copeland, M.M. (1945) Diseases of the Breast: Diagnosis, Pathology, and Treatment. J. B. Lippincott, Philadelphia.

[3] Li, N., Xu, L., Zhao, H., El-Naggar, A.K. and Sturgis, E.M. (2012) A Comparison of the Demographics, Clinical Features, and Survival of Patients with Adenoid Cystic Carcinoma of Major and Minor Salivary Glands versus Less Common Sites within the Surveillance, Epidemiology, and End Results Registry. Cancer, 118, 3945-3953. http://dx.doi.org/10.1002/cncr.26740

[4] Dinkel, H.-P., Clees, M. and Gassel, A.M. (1999) Role of Sonography in Detecting Recurrence in Adenoid Cystic Carcinoma of the Breast. AJR, 173, 497-498. http://dx.doi.org/10.2214/ajr.173.2.10430162

[5] Santamaria, G., Velasco, M., Zanon, G., Farrus, B., Molina, R., Sole, M., et al. (1998) Adenoid Cystic Carcinoma of the Breast: Mammographic Appearance and Pathologic Correlation. AJR, 171, 1679-1683.

[6] Sperber, F., Blank, A. and Metser, U. (2002) Adenoid Cystic Carcinoma of the Breast: Mammographic, Sonographic, and Pathological Correlation. The Breast Journal, 8, 53-54. http://dx.doi.org/10.1046/j.1524-4741.2002.08012.X

[7] Youk, J.H., Kim, M.J., Kim, E.-K., Lee, J.Y., Oh, K.K. and Park, B.W. (2006) Recurrence of Adenoid Cystic Carcinoma of the Breast after Lumpectomy and Adjuvant Therapy. Journal of Ultrasound in Medicine, 25, 921-924.

[8] Sumpio, B.E., Jennings, T.A., Merino, M.J. and Sullivan, P.D. (1987) Adenoid Cystic Carcinoma of the Breast. Data from the Connecticut Tumor Registry and a Review of the Literature. Annals of Surgery, 205, 295-301. http://dx.doi.org/10.1097/00000658-198703000-00013

[9] Azoulay, S., Laé, M., Fréneaux, P., Merle, S., Al Ghuslan, A., Chnecker, C., et al. (2005) KIT Is Highly Expressed in Adenoid Cystic Carcinoma of the Breast, a Basal-Like Carcinoma Associated with a Favourable Outcome. Modern Pathology, 18, 1623-1631.

[10] Weigelt, B., Horlings, H.M., Kreike, B., Hauptmann, M., Wessels, L.F.A., de Jong, D., et al. (2008) Refinement of Breast Cancer Classification by Molecular Characterization of Histological Specila Types. The Journal of Pathology, 216, 141-150. http://dx.doi.org/10.1002/path.2407

[11] Leeming, R., Jenkins, M. and Mendelsohn, G. (1992) Adenoid Cystic Carcinoma of the Breast. Archives of Surgery, 127, 233-235. http://dx.doi.org/10.1001/archsurg.1992.01420020127019

[12] McClenathan, J.H. and de la Roza, G. (2002) Adenoid Cystic Breast Cancer. The American Journal of Surgery, 183, 646-649. http://dx.doi.org/10.1016/S0002-9610(02)00858-9

[13] Boujelbene, N., Khabir, A., Boujelbene, N., Jeanneret Sozzi, W., Mirimanoff, R.O. and Khanfir, K. (2012) Clinical Review: Breast Adenoid Cystic Carcinoma. Breast, 21, 124-127. http://dx.doi.org/10.1016/j.breast.2011.11.006

[14] Coates, J.M., Martinez, S.R., Bold, R.J. and Chen, S.L. (2010) Adjuvant Radiation Therapy Is Associated with Improved Survival for Adenoid Cystic Carcinoma of the Breast. Journal of Surgical Oncology, 102, 342-347. http://dx.doi.org/10.1002/jso.21638

[15] Goldhirsch, A., Winer, E.P., Coates, A.S., Gelber, R.D., Piccart-Gebhart, M., Thürlimann, B. and Senn, H.-J. (2013) Personalizing the Treatment of Women with Early Breast Cancer: Highlights of the St Gallen International Expert Consensus on the Primary Therapy of Early Breast Cancer. Annals of Oncology, 24, 2206-2223. http://dx.doi.org/10.1093/annonc/mdt303

[16] Senkus, E., Kyriakides, S., Penault-Llorca, F., Poortmans, P., Thompson, A., Zackrisson, S. and Cardoso, F. on Behalf of the ESMO Guidelines Working Group (2013) Primary Breast Cancer: ESMO Clinical Practice Guidelines for Diagnosis, Treatment and Follow-Up. Annals of Oncology, 24, vi7-vi23. http://dx.doi.org/10.1093/annonc/mdt284

[17] Weigelt, B., Horlings, H.M., Kreike, B., Hauptmann, M., Wessels, L.F.A., de Jong, D., et al. (2008) Refinement of Breast Cancer Classification by Molecular Characterization of Histological Specila Types. The Journal of Pathology, 216, 141-150. http://dx.doi.org/10.1002/path.2407

[18] Arpino, G., Clark, G.M., Mohsin, S., Bardou, V.J. and Elledge, R.M. (2002) Adenoid Cystic Carcinoma of the Breast: Molecular Markers, Treatment, and Clinical Outcome. Cancer, 94, 2119-2127. http://dx.doi.org/10.1002/cncr.10455 
Scientific Research Publishing (SCIRP) is one of the largest Open Access journal publishers. It is currently publishing more than 200 open access, online, peer-reviewed journals covering a wide range of academic disciplines. SCIRP serves the worldwide academic communities and contributes to the progress and application of science with its publication.

Other selected journals from SCIRP are listed as below. Submit your manuscript to us via either submit@scirp.org or Online Submission Portal.
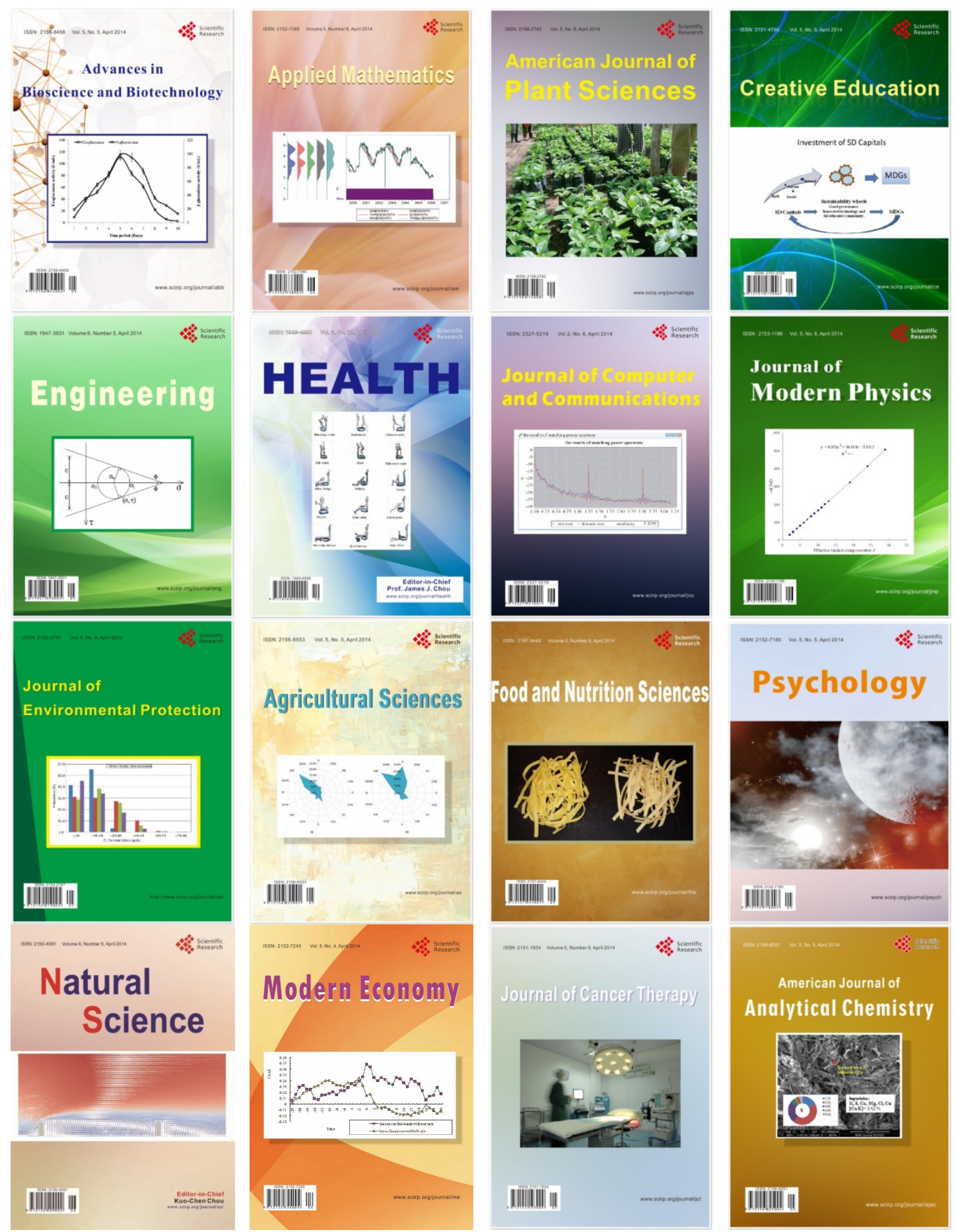